\title{
HBCO CORRECTION: ITS IMPACT ON ARCHAEOLOGICAL ABSOLUTE DATING
}

\author{
Peter Barta
}

Dendrochronological Laboratory, Bratislava, Slovak Republic. Corresponding author. Email: barta@kuwaitarchaeology.org.

Svorad Štolc Jr

Institute of Measurement Science, Slovak Academy of Sciences, Bratislava, Slovak Republic. Email: umerstol@savba.sk.

\begin{abstract}
When constructing absolute chronologies in archaeology, the aim is to detect archaeological events. In this respect, we draw attention to the relation between the radiocarbon ages of human bone collagen samples and the absolute dating evidence on the age at death. In recent material, Mebus Geyh (2001a,b) described the offset between the former and the latter, and suggested the relevant correction. The corrected ${ }^{14} \mathrm{C}$ ages pertain to the age of the individual at death.

We have developed an application of Geyh's original observation, which we term the human bone collagen offset (HBCO) correction, to apply to archaeological ${ }^{14} \mathrm{C}$ dates. If the death and interment of individuals are identical, the corrected ${ }^{14} \mathrm{C}$ date reliably informs us about the deposition of the body and accompanying grave goods. In archaeology, the concrete correction value is determined by the anthropologically estimated age of the individual, which we model by a normal (Gaussian) distribution. The eventual impact of the HBCO correction on archaeological chronology depends on the portion of the calibration curve through which the $\mathrm{HBCO}$-corrected date is calibrated. At a certain level of ${ }^{14} \mathrm{C}$ measurement precision, the difference between the $\mathrm{HBCO}$-corrected and non-corrected calendar dates can be considerable.
\end{abstract}

\section{INTRODUCTION}

When radiocarbon dates measured on human bone collagen are used in archaeology, it is assumed that the sample material is of a short-lived nature. The dates are believed to be associated closely with the archaeological event. However, human bone, due to its specific physiology, is a complex material. It archives the dietary and health history of the individual's life, and this may affect the reliability of any absolute date (e.g. Geyh 2001a; Cook et al. 2002). As for the formation period, Geyh (2001a, personal communication 2004) has proposed a model for ${ }^{14} \mathrm{C}$ turnover in human bone collagen, and a correction for an associated offset. Suggesting that ${ }^{14} \mathrm{C}$ ages on human bone collagen represent the termination of puberty rather than the age at death, the work has strong implications for construction of absolute chronologies (Geyh 2001a,b). Accordingly, the assumption that human bone collagen represents a short-lived sample is an oversimplification and may well be misleading.

In our paper, Geyh's correction (2001a), which we term the human bone collagen offset (HBCO) correction, is applied to archaeological samples. Given the original observation (Geyh 2001a, personal communication 2004), we put forth a mechanism to improve the accuracy of collagen chronologies. First, we address Geyh's model, which is based on recent material. Second, we develop a statistical representation of skeletal age classes in order to arrive at concrete correction terms. Finally, we illustrate the impact of the HBCO correction and discuss the caveats and limitations of the suggested correction procedure.

\section{THE MODEL OF MEBUS GEYH}

Geyh's (2001a) model is based on the bomb ${ }^{14} \mathrm{C}$ dating of 48 individuals of known birth and death dates. In accordance with earlier works, Geyh modeled carbon exchange in human bone in 2 physiological periods - the growth phase and the aging phase (2001a,b, personal communication 2004). During the growth phase, he assumed a turnover of 5\% per year. This main carbon uptake in human bone collagen slows down at the end of puberty at $19 \mathrm{yr}$. Throughout the course of the subsequent aging phase, the carbon exchange rate is assumed to be around $1.5 \%$. Hence, ${ }^{14} \mathrm{C}$ dates measured on 
human bone collagen represent the termination of puberty rather than the date of death (Figure 1). Therefore, Geyh (2001a,b) advised the correction of any conventional ${ }^{14} \mathrm{C}$ date measured from the human bone collagen of an adult individual, if it is to bring evidence on the date of death. The correction term value depends on the age of the individual at death. The real ${ }^{14} \mathrm{C}$ age is obtained by subtracting the correction term from the measured conventional date (Geyh 2001a, personal communication 2004).

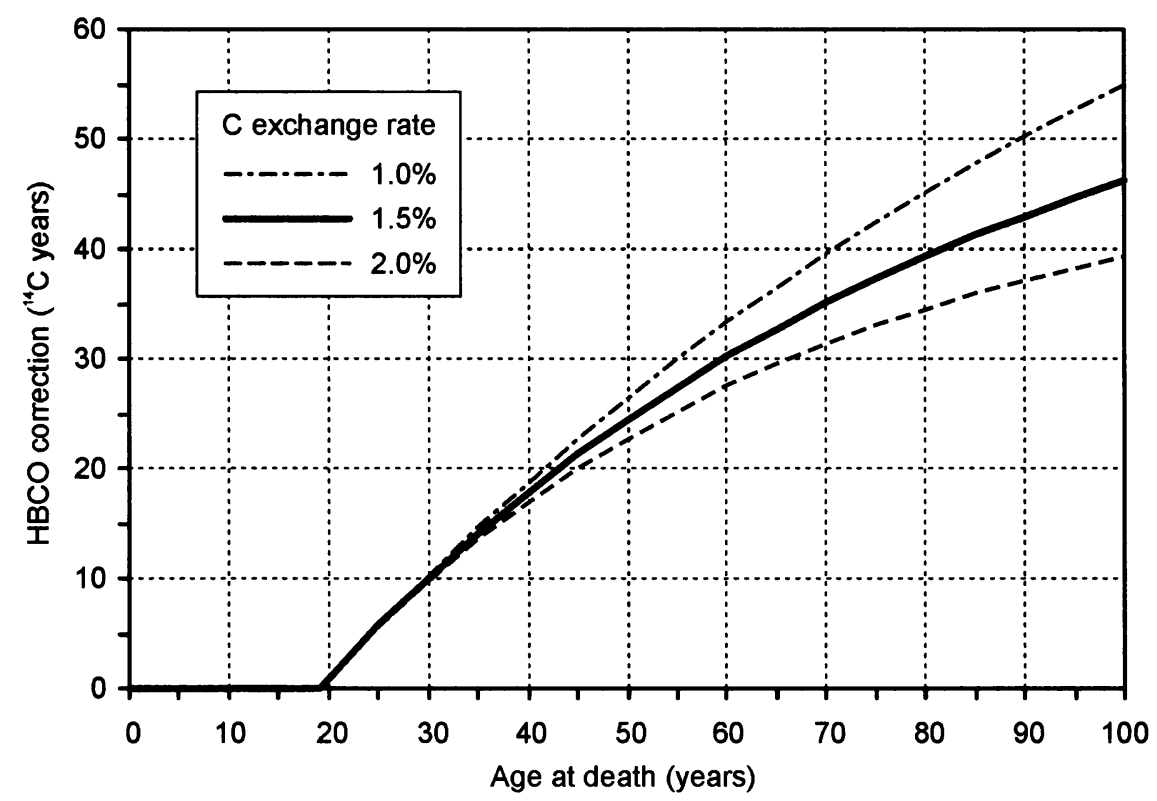

Figure 1 The HBCO correction term as suggested by Geyh (2001a,b, personal communication 2004) is the nonlinear relationship between the age at death of an individual and the correction of the conventional ${ }^{14} \mathrm{C}$ date. The model reflects 2 phases of carbon uptake in human bones: the growth phase $(0-19 \mathrm{yr})$ and the aging phase ( $\geq 20 \mathrm{yr})$. The correction term is calculated for 3 different carbon exchange rates during the aging phase: $1 \%, 1.5 \%$, and $2 \%$.

To make use of this model in archaeology, we should first express the age of an individual at death by the physical anthropologist's expertise at aging human skeletal remains. Second, one ought to consider the dietary history of the individual, which is an important influence on the bone collagen ${ }^{14} \mathrm{C}$ activity. Despite Cook et al.'s (2002) recommendations, routine measurements of ${ }^{15} \mathrm{~N}$ paired with ${ }^{14} \mathrm{C}$ dating of archaeological human bones are still uncommon. Hence, we assume that the archaeological samples that are to be $\mathrm{HBCO}$-corrected have a specific ${ }^{14} \mathrm{C}$ activity comparable to the coeval atmosphere.

\section{STATISTICAL REPRESENTATION OF SKELETAL AGE CLASSES}

To arrive at the HBCO correction values for archaeological bones, the age of the individual at death is described by the physical anthropologist's estimate of skeletal age. Next, the statistical representation of skeletal age classes is passed through Geyh's correction term (2001a) to obtain respective correction values.

The physical anthropologist's estimates are typically with a precision of decades (Infans, Juvenilis, Adultus, Maturus, and Senilis). For our purposes, we express this age uncertainty by the normal 
(Gaussian) distribution and propose 2 models representing different confidence levels relating to the age estimate derived by anthropological means:

- Model A presumes that the true skeletal age comes from the estimated range with $68.2 \%$ probability $( \pm 1 \sigma)$ (Figure 2a).

- Model B presumes this probability to be $95.4 \%$ ( $\pm 2 \sigma)$ (Figure $2 b$ ).
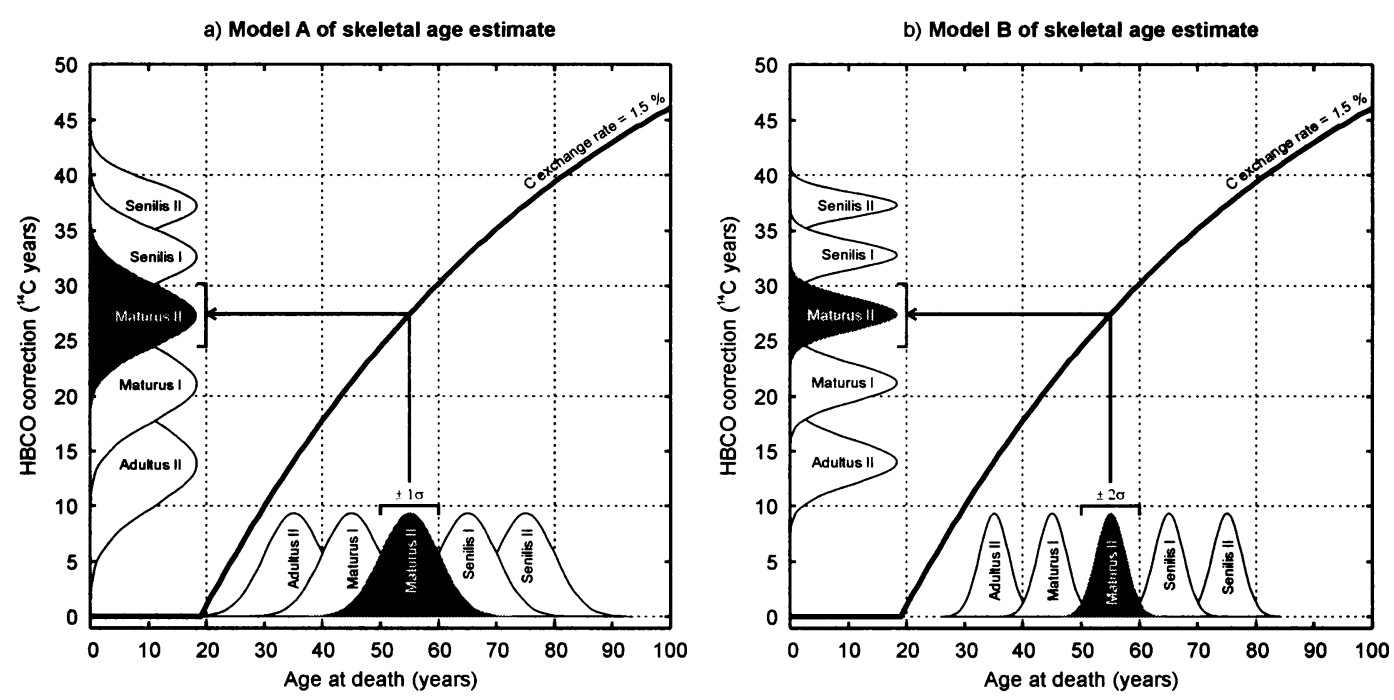

Figure 2 Two models representing the physical anthropologist's estimates of skeletal age: a) Model A; b) Model B. Gaussians on the abscissa represent individual skeletal age classes. Gaussians on the ordinate represent approximations of the nonnormal distributions generated by Geyh's (2001a) model.

Obviously, Model A is less strict and therefore provides less accurate $\mathrm{HBCO}$ correction. It is to be used when the skeletal age estimate is less certain. On the other hand, Model B provides more accurate $\mathrm{HBCO}$ correction, dependent on a more precise estimate of skeletal age.

As the HBCO correction term (Geyh 2001a,b) is a nonlinear relationship, it does not strictly preserve the distribution of the age estimate. The curve transforms both the A and B models of skeletal age estimates to realistic non-normal distributions of the $\mathrm{HBCO}$ correction values. While for some age classes the transformed distributions can be very complicated, others turn out to be close to normal. Accordingly, these can be approximated by simple Gaussian models (Figure 2a,b).

To demonstrate the suitability of the Gaussian approximations, all transformed distributions were tested using the Lilliefors non-parametric test for the goodness of fit to normal distribution at a significance level of 5\% (Conover 1980). The test was performed on 1000 simulated populations, each consisting of 1000 samples. When the normality was rejected for more than $50 \%$ of the simulations, it was regarded as rejected for the whole age class. While the normality was rejected for most skeletal age classes of Model A (Table 1), this was not so for the majority of age classes using Model B (Table 2). In the latter case, the Gaussian models matched the realistic distributions rather well. However, one should keep in mind that the result of this assessment is strongly affected by the size of the tested population. 
Table 1 The HBCO correction values calculated for Model A. The Lilliefors test rejects normality of distributions generated by Geyh's model for most skeletal age classes. Therefore, we suppose that Gaussian approximation of HBCO correction is applicable mainly for classes Infans I, Adultus II, Maturus I and II, and Senilis I and II.

\begin{tabular}{llcccl}
\hline Class & Label & $\begin{array}{l}\text { Age at death } \\
\text { (calendar yr) }\end{array}$ & $\begin{array}{l}\text { Model A } \\
\text { (calendar yr) }\end{array}$ & $\begin{array}{l}\text { HBCO correction } \\
\left({ }^{14} \mathrm{C} \text { yr }\right)\end{array}$ & Lilliefors test \\
\hline Infans & I-A & $0-13$ & $6.5 \pm 6.5$ & $0.08 \pm 0.57$ & normality rejected \\
- Infans I & I1-A & $0-6$ & $3 \pm 3$ & $0.00 \pm 0.00$ & - \\
- Infans II & I2-A & $6-13$ & $9.5 \pm 3.5$ & $0.00 \pm 0.08$ & normality rejected \\
Juvenilis & J-A & $13-20$ & $16.5 \pm 3.5$ & $0.47 \pm 1.15$ & normality rejected \\
Adultus & A-A & $20-40$ & $30 \pm 10$ & $10.10 \pm 7.15$ & normality rejected \\
- Adultus I & A1-A & $20-30$ & $25 \pm 5$ & $5.78 \pm 4.01$ & normality rejected \\
- Adultus II & A2-A & $30-40$ & $35 \pm 5$ & $13.90 \pm 3.90$ & - \\
Maturus & M-A & $40-60$ & $50 \pm 10$ & $23.97 \pm 6.27$ & normality rejected \\
- Maturus I & M1-A & $40-50$ & $45 \pm 5$ & $21.12 \pm 3.35$ & - \\
- Maturus II & M2-A & $50-60$ & $55 \pm 5$ & $27.32 \pm 2.88$ & - \\
Senilis & S-A & $60-80$ & $70 \pm 10$ & $34.75 \pm 4.63$ & normality rejected \\
- Senilis I & S1-A & $60-70$ & $65 \pm 5$ & $32.65 \pm 2.47$ & - \\
- Senilis II & S2-A & $70-80$ & $75 \pm 5$ & $37.24 \pm 2.13$ & - \\
\hline
\end{tabular}

Table 2 The HBCO correction values calculated for Model B. The Lilliefors test rejects normality for Juvenilis only. Accordingly, the Gaussian approximation of HBCO correction is applicable mainly for all other classes.

\begin{tabular}{lllccl}
\hline Class & Label & $\begin{array}{l}\text { Age at death } \\
\text { (calendar yr) }\end{array}$ & $\begin{array}{l}\text { Model B } \\
\text { (calendar yr) }\end{array}$ & $\begin{array}{l}\text { HBCO correction } \\
\left({ }^{14} \mathrm{C} \text { yr) }\right.\end{array}$ & Lilliefors test \\
\hline Infans & I-B & $0-13$ & $6.5 \pm 3.25$ & $0.00 \pm 0.01$ & - \\
- Infans I & I1-B & $0-6$ & $3 \pm 1.5$ & $0.00 \pm 0.00$ & - \\
- Infans II & I2-B & $6-13$ & $9.5 \pm 1.75$ & $0.00 \pm 0.00$ & - \\
Juvenilis & J-B & $13-20$ & $16.5 \pm 1.75$ & $0.06 \pm 0.28$ & normality rejected \\
Adultus & A-B & $20-40$ & $30 \pm 5$ & $9.88 \pm 4.14$ & - \\
- Adultus I & A1-B & $20-30$ & $25 \pm 2.5$ & $5.63 \pm 2.24$ & - \\
- Adultus II & A2-B & $30-40$ & $35 \pm 2.5$ & $14.01 \pm 1.94$ & - \\
Maturus & M-B & $40-60$ & $50 \pm 5$ & $24.34 \pm 3.10$ & - \\
- Maturus I & M1-B & $40-50$ & $45 \pm 2.5$ & $21.21 \pm 1.67$ & - \\
- Maturus II & M2-B & $50-60$ & $55 \pm 2.5$ & $27.41 \pm 1.43$ & - \\
Senilis & S-B & $60-80$ & $70 \pm 5$ & $35.03 \pm 2.29$ & - \\
- Senilis I & S1-B & $60-70$ & $65 \pm 2.5$ & $32.72 \pm 1.23$ & - \\
- Senilis II & S2-B & $70-80$ & $75 \pm 2.5$ & $37.30 \pm 1.06$ & - \\
\hline
\end{tabular}

\section{${ }^{14} \mathrm{C}$ CALIBRATION OF HBCO-CORRECTED DATES USING RESERVOIR OFFSETS}

The reservoir correction enables the application of calibration data suitable for one reservoir to the samples from another reservoir. A reservoir offset itself is represented by the mean shift between primary and secondary reservoirs and its standard error.

Accordingly, calibration of HBCO-corrected ${ }^{14} \mathrm{C}$ dates can be carried out as the application of a specific reservoir offset onto the atmospheric calibration data set. The age difference between corrected and non-corrected ${ }^{14} \mathrm{C}$ dates is recognized as a reservoir offset that is specific for each individual. If the age at death of a dated individual is precisely known, the appropriate reservoir offset can be directly read from Geyh's model as the correction value with 0 standard error (Figure 1). This is obviously not the case for archaeological human remains, where the anthropologist's age estimate usually has a precision of decades. This uncertainty results in reservoir offsets with non-zero standard errors requiring a more complex approach (see section "Statistical representation of skeletal age classes"). 
Jones and Nicholls (2001) pointed out several critical issues about reservoir correction as defined by Stuiver and Braziunas (1993). Whereas samples coming from a common reservoir are dependent considering the same reservoir offset, the application of an independent reservoir offset with a standard error $>0$ may lead to significant calculation errors. In the case of HBCO correction, each dated individual is viewed as an independent reservoir with its own specific reservoir offset. Therefore, samples taken from different individuals are clearly independent. On the other hand, when more samples taken from the same individual are calibrated, the arguments of Jones and Nicholls (2001) have to be taken into account.

\section{RESULTS}

Regarding calculation of the HBCO correction, we present 2 tables that introduce appropriate HBCO-correction coefficients for all common skeletal age classes. Table 1 summarizes results obtained for the Model A of skeletal age estimates. The Lilliefors test rejects normality of the realistic distributions generated by Geyh's model for most skeletal age classes. Therefore, we suppose that the Gaussian approximation of HBCO correction is applicable mainly for classes Infans I, Adultus II, Maturus I and II, and Senilis I and II. Results obtained for Model B are summarized in Table 2. In this case, however, the Lilliefors test rejects normality for just 1 skeletal age class-Juvenilis. Accordingly, the approximate HBCO correction is applicable mainly for all other age classes.

In archaeological practice, we suggest implementation of the $\mathrm{HBCO}$ correction in ${ }^{14} \mathrm{C}$ calibration by means of the $\Delta \mathrm{R}$ command available in many calibration tools (e.g. OxCal, BCal, CALIB). The eventual impact of the correction on archaeological chronologies depends on the portion of the calibration curve through which a corrected ${ }^{14} \mathrm{C}$ date is calibrated. By virtue of the HBCO correction, an original ${ }^{14} \mathrm{C}$ age may be shifted to a high gradient or a wiggly part of the calibration curve. This, in turn, may generate a considerably different calendar date that is difficult to predict. Therefore, we feel it justified to employ the HBCO correction in building absolute chronologies incorporating human bone collagen ${ }^{14} \mathrm{C}$ dates.

\section{ARCHAEOLOGICAL EXAMPLES}

In order to demonstrate the impact of the $\mathrm{HBCO}$ correction on archaeological chronologies, we demonstrate 2 common situations that an archaeologist may encounter: 1) the calibration of single determinations and 2) the complex Bayesian model. For the former, we have chosen 4 human bone collagen determinations from Early Bronze Age (EBA) sites around Stuttgart, Baden-Württemberg (Krause 1996). For the latter, we have used 10 human bone collagen dates from 10 graves of an EBA cemetery at Singen, Lake Constance (Bodensee) (Krause 1988; Becker et al. 1989). The latter played a key role in debates about continental EBA chronology in the late 1980s and early 1990s (Barta 2006).

For the 4 high-precision ${ }^{14} \mathrm{C}$ dates that were published without information on the age of the deceased (Krause 1996), we visualized the magnitude of the shift on the calendar timescale by simulation of different skeletal age classes. The samples come from grave 1/1 at Gäufelden-Tailfingen (Hd-11794), grave 1/1 at Weinstadt-Endersbach (Hd-11774), grave 12 at Remseck-Aldingen (Hd13984), and grave 1/1 at Gerlingen (Hd-11855). Considerable changes in posterior probability distributions triggered by the $\mathrm{HBCO}$ correction are clearly visible (Figure 3 ). Following the simulations, if the anthropologically estimated age at death is not taken into account, the absolute chronological conclusion drawn by the archaeologist may very well not be correct. 

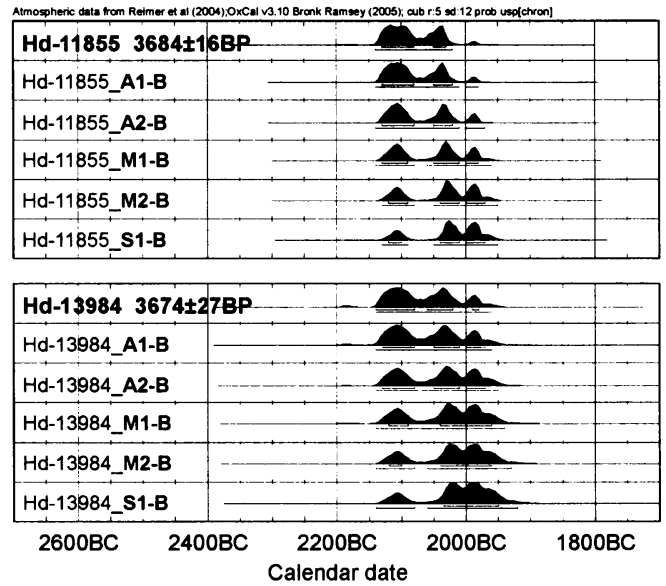
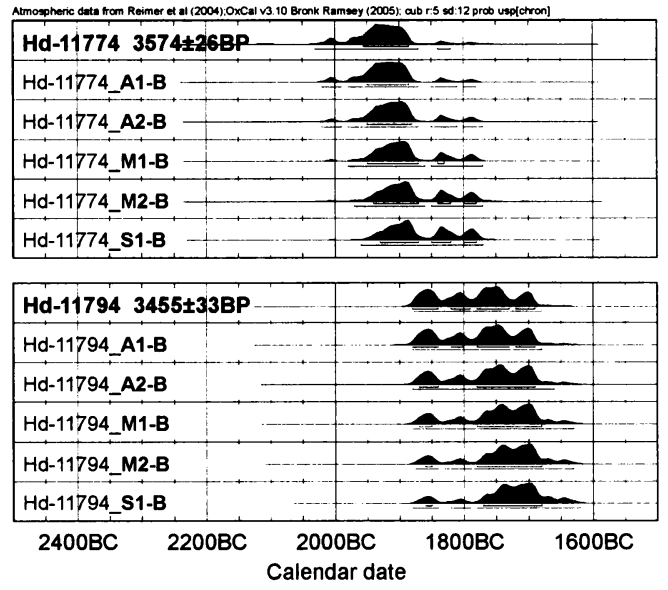

Figure $3{ }^{14} \mathrm{C}$ dates and associated HBCO correction simulations for skeletal age classes Adultus I and II, Maturus I and II, and Senilis I. ${ }^{14} \mathrm{C}$ samples come from grave $1 / 1$ at Gerlingen (Hd-11855), grave $1 / 1$ at Weinstadt-Endersbach (Hd11774), grave 12 at Remseck-Aldingen (Hd-13984), and grave $1 / 1$ at Gäufelden-Tailfingen (Hd-11794), Early Bronze Age, south Germany. For labels of the skeletal age classes, see Tables 1 and 2. Calibration was done using OxCal v 3.10 (Bronk Ramsey 1995, 2001) and the IntCal04 calibration curve (Reimer et al. 2004).

In the second example, the difference between HBCO-corrected and non-corrected data is not so marked as in the first example (Figure 4). This is partly due to the larger standard deviations of the conventional dates used $\left(40-50{ }^{14} \mathrm{C} \mathrm{yr}\right)$. The probability distributions marking the start and end of burial at the Singen cemetery were modified only slightly. Nonetheless, the distributions for the start of burial have changed from bimodal to unimodal, suggesting a shift of 60 calendar yr. The posterior probability peak for the end of burial has shifted by 40 calendar yr.

a) HBCO non-corrected data

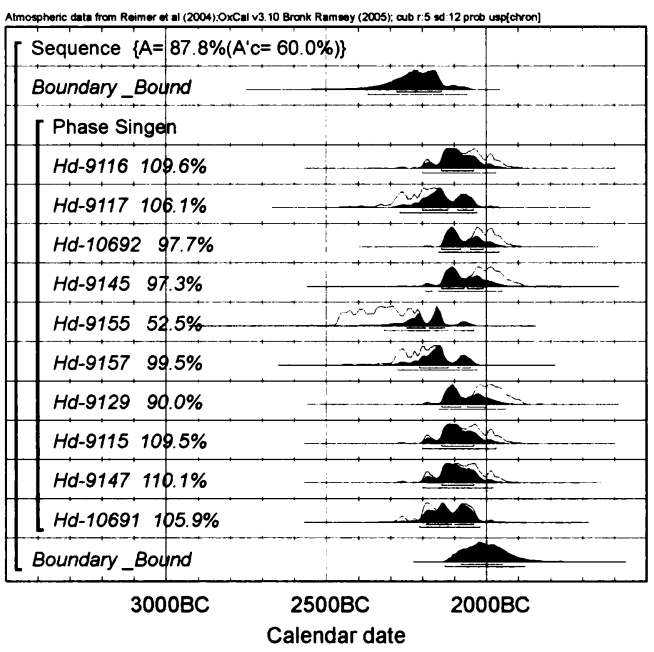

b) HBCO corrected data

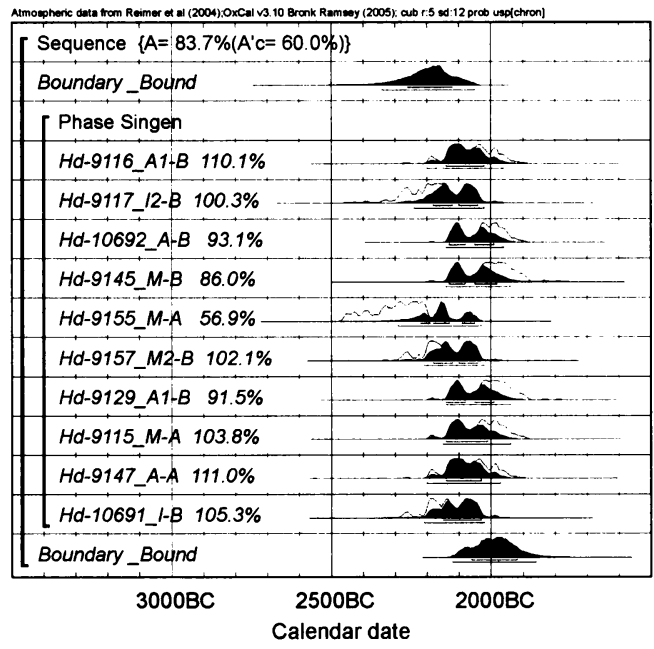

Figure 4 EBA cemetery at Singen, south Germany. Note the difference between posterior probability distributions of $\mathrm{HBCO}$ a) non-corrected and b) corrected ${ }^{14} \mathrm{C}$ dates. The start and the end of burial at the cemetery has shifted by 60 and 40 calendar yr, respectively. Standard errors of the conventional dates range between $40-50{ }^{14} \mathrm{C}$ yr. For labels of the skeletal age classes, see Tables 1 and 2. Calibration was done using OxCal v 3.10 (Bronk Ramsey 1995, 2001) and the IntCal04 calibration curve (Reimer et al. 2004). 


\section{DISCUSSION AND CONCLUSION}

Notwithstanding the complexity of the topic and the new models for carbon turnover in human bone collagen, we suggest that the use of the HBCO correction in archaeology is advisable, and recommend it when constructing absolute chronologies based on age-at-death information. In contrast, by using the human bone collagen ${ }^{14} \mathrm{C}$ dates without the $\mathrm{HBCO}$ correction, archaeologists run the risk that the calendar date probability distribution obtained will not be accurate. Moreover, the wiggles and high-gradient regions of the calibration curve make the impact of the HBCO correction difficult to foresee.

The proposed correction mechanism is biased by the limitations of the original model. As noted by Geyh $(2001 \mathrm{a}, \mathrm{b})$, the paucity of knowledge concerning carbon uptake and residence time in animal tissues may cause problems in application of the HBCO correction. Moreover, there seem to be differences within and between organs of animals, as well as between individuals. This topic has most recently been considered by Hedges et al. (2006). Having studied the samples from the femoral midshafts of 67 individuals, they concluded that the specific ${ }^{14} \mathrm{C}$ activity of the collagen between males and females is significantly different, and that the turnover rate during growth depends on the geometric growth of the bone.

Finally, we should mention diet-derived ${ }^{14} \mathrm{C}$ age offsets (e.g. aquatic diet). This may be more of an influence on accuracy than the human bone collagen offset, but ${ }^{14} \mathrm{C}$ dates paired with dietary analyses are still rare in archaeology. Therefore, at present, the HBCO correction may effectively contribute to improved accuracy for the majority of ${ }^{14} \mathrm{C}$ dates of archaeological human remains.

\section{ACKNOWLEDGMENTS}

The authors express their sincere gratitude to Professor Mebus Geyh (Hannover), who provided newly calculated HBCO correction values. Without his help and encouraging discussions at the Ustron Conference (2004), the work would have not appeared in the present form. PB wishes to thank Professor Hermann Parzinger (President, Deutsches Archäologisches Institut) and Dr KarlUwe Heußner (Deutsches Archäologisches Institut, Dendrochronologisches Labor) for their strong support during the 2004 internship at DAI Zentrale (Berlin), where the outline of the present paper was written. Finally, the authors are indebted to Dr Chris Bronk Ramsey, Dr Alex Bayliss (Oxford 2006), and 2 anonymous reviewers for their comments and suggestions.

This research was supported by private donors from Slovakia and the Slovak Grant Agency for Science (grant $\mathrm{nr} 2 / 4026 / 04)$.

\section{REFERENCES}

Barta P. 2006. Studies on absolute chronology of the Bronze Age in east-central Europe: methods and applications [PhD dissertation manuscript]. Nitra: Slovak Academy of Sciences, Institute of Archaeology.

Becker B, Krause R, Kromer B. 1989. Zur absoluten Chronologie der frühen Bronzezeit. Germania 67(2): 421-42. In German.

Bronk Ramsey C. 1995. Radiocarbon calibration and analysis of stratigraphy: the OxCal program. Radiocarbon 37(2):425-30.

Bronk Ramsey C. 2001. Development of the radiocarbon program. Radiocarbon 43(2A):355-63.

Conover WJ. 1980. Practical Nonparametric Statistics. 2nd edition. New York: John Wiley and Sons, Inc. $512 \mathrm{p}$.

Cook GT, Bonsall C, Hedges REM, McSweeney K, Boroneanţ V, Bartosiewicz L, Pettitt PB. 2002. Problems of dating human bones from the Iron Gates. Antiquity 76(291):77-85.

Geyh MA. 2001a. Bomb radiocarbon dating of animal tissues and hair. Radiocarbon 43(2B):723-30.

Geyh MA. 2001b. Symbiosis between geochronologists and Quaternary geoscientists. Geochronometria 20:18.

Hedges REM, O'Connell TC, Clement JG. 2006. Collagen turnover in adult femoral bone using the $1960 \mathrm{~s}$ 
nuclear bomb test radiocarbon production as a dietary tracer [abstract \#40]. 19th International Radiocarbon Conference, Keble College, Oxford, 3-7 April 2006.

Jones M, Nicholls G. 2001. Reservoir offset models for radiocarbon calibration. Radiocarbon 43(1):119-24.

Krause R. 1988. Die endneolithischen und frühbronzezeitlichen Grabfunde auf der Nordstadtterrasse von Singen am Hohentwiel. Forschungen und Berichte zur Vor- und Frühgeschichte in Baden-Württemberg,
Band 32. Stuttgart: Konrad Theiss Verlag. In German. Krause R. 1996. Zur Chronologie der frühen und mittleren Bronzezeit Süddeutschlands, der Schweiz und Österreichs. Acta Archaeologica 67 (Supplementum I):73-86. In German.

Stuiver M, Braziunas TF. 1993. Modeling atmospheric ${ }^{14} \mathrm{C}$ influences and ${ }^{14} \mathrm{C}$ ages of marine samples to 10,000 BC. Radiocarbon 35(1):137-89. 